\title{
Public attitudes toward stuttering in Europe: within-country and between- country comparisons
}

Article

Accepted Version

Creative Commons: Attribution-Noncommercial-No Derivative Works 4.0

St Louis, K. O., Sønsterud, H., Junuzović-Žunić, L., Tomaiuoli, D., Del Gado, F., Caparelli, E., Theiling, M., Flobakk, C., Helmen, L. N., Heitmann, R. R., Kvenseth, H., Nilsson, S., Wetterling, T., Lundström, C., Daly, C., Leahy, M., Tyrrell, L., Ward, D. and Węsierska, M. (2016) Public attitudes toward stuttering in Europe: within-country and between-country comparisons. Journal of Communication Disorders, 62. pp. 115-130. ISSN 0021-9924 doi:

https://doi.org/10.1016/j.jcomdis.2016.05.010 Available at https://centaur.reading.ac.uk/66134/

It is advisable to refer to the publisher's version if you intend to cite from the work. See Guidance on citing.

To link to this article DOI: http://dx.doi.org/10.1016/j.jcomdis.2016.05.010

Publisher: Elsevier

All outputs in CentAUR are protected by Intellectual Property Rights law, including copyright law. Copyright and IPR is retained by the creators or other copyright holders. Terms and conditions for use of this material are defined in the End User Agreement. 


\section{www.reading.ac.uk/centaur}

\section{CentAUR}

Central Archive at the University of Reading

Reading's research outputs online 


\section{Accepted Manuscript}

Title: Public Attitudes Toward Stuttering in Europe:

Within-Country and Between-Country Comparisons

Author: Kenneth O. St. Louis Hilda Sønsterud Lejla

Junuzović-Žunić Donatella Tomaiuoli Francesca DelGado

Emilia Caparelli Mareen Theiling Cecilie Flobakk Lise

Nesbakken Helmen Ragnhild R. Heitmann Helene Kvenseth

Sofia Nilsson Tobias Wetterling Cecilia Lundström Ciara Daly

Margaret Leahy Laila Tyrrell David Ward Marta Węsierska

PII:

S0021-9924(16)30041-7

DOI: http://dx.doi.org/doi:10.1016/j.jcomdis.2016.05.010

Reference: JCD 5767

To appear in: $\quad J C D$

Received date: $\quad 18-5-2015$

Revised date: $\quad 17-5-2016$

Accepted date: $\quad$ 24-5-2016

Please cite this article as: St.Louis, Kenneth O., Sønsterud, Hilda., JunuzovićŽunić, Lejla., Tomaiuoli, Donatella., DelGado, Francesca., Caparelli, Emilia., Theiling, Mareen., Flobakk, Cecilie., Helmen, Lise Nesbakken., Heitmann, Ragnhild R., Kvenseth, Helene., Nilsson, Sofia., Wetterling, Tobias., Lundström, Cecilia., Daly, Ciara., Leahy, Margaret., Tyrrell, Laila., Ward, David., \& Węsierska, Marta., Public Attitudes Toward Stuttering in Europe: WithinCountry and Between-Country Comparisons.Journal of Communication Disorders http://dx.doi.org/10.1016/j.jcomdis.2016.05.010

This is a PDF file of an unedited manuscript that has been accepted for publication. As a service to our customers we are providing this early version of the manuscript. The manuscript will undergo copyediting, typesetting, and review of the resulting proof before it is published in its final form. Please note that during the production process errors may be discovered which could affect the content, and all legal disclaimers that apply to the journal pertain. 


\title{
Public Attitudes Toward Stuttering in Europe: Within-Country and Between-Country Comparisons
}

\author{
Kenneth O. St. Louis ${ }^{\text {a }}$ \\ Hilda Sønsterud ${ }^{\mathrm{b}}$ \\ Lejla Junuzović-Žunić ${ }^{c}$ \\ Donatella Tomaiuoli $^{\mathrm{d}}$ \\ Francesca DelGado ${ }^{\mathrm{e}}$ \\ Emilia Caparelli ${ }^{\mathrm{f}}$ \\ Mareen Theiling ${ }^{g}$ \\ Cecilie Flobakk ${ }^{\mathrm{h}}$ \\ Lise Nesbakken Helmen ${ }^{\mathrm{i}}$ \\ Ragnhild R. Heitmann ${ }^{j}$ \\ Helene Kvenseth ${ }^{\mathrm{k}}$ \\ Sofia Nilsson ${ }^{1}$ \\ Tobias Wetterling ${ }^{\mathrm{m}}$ \\ Cecilia Lundström ${ }^{\mathrm{n}}$ \\ Ciara Daly ${ }^{\circ}$ \\ Margaret Leahy ${ }^{p}$ \\ Laila Tyrrell $^{\mathrm{q}}$ \\ David Ward $^{\mathrm{r}}$ \\ Marta Węsierska ${ }^{\mathrm{s}}$
}

\section{Corresponding Author}

${ }^{a}$ West Virginia University, Morgantown, West Virginia, USA

Department of Communication Sciences \& Disorders

805 Allen Hall, PO Box 6122

West Virginia University

Morgantown, WV 26506-6122

Email: ken.stlouis@mail.wvu.edu

Telephone: +1-304-293-2946

FAX: +1-304-293-2905

${ }^{\mathrm{b}}$ Statped, Staped, Department of Speech and Language Disorders, Oslo, Norway <hilda.sonsterud@statped.no>

${ }^{\mathrm{c}}$ University of Tuzla, Tuzla, Bosnia \& Herzegovina

$<$ j.lejla@gmail.com>

${ }^{\mathrm{d}}$ CRC Balbuzie and University of Rome, Italy <d.tomaiuoli@crc-balbuzie.it> 
${ }^{\mathrm{e}}$ CRC Balbuzie, Rome, Italy <f.delgado@crc-balbuzie.it>

${ }^{\mathrm{f}}$ CRC Balbuzie, Rome, Italy <e.caparelli@crc-balbuzie.it>

${ }^{\mathrm{g}}$ Rheinisch Westfälische Technische Hochschule Aachen (RWTH Aachen University), Germany $<$ mareen.theiling@rwth-aachen.de>

${ }^{\mathrm{h}}$ Aakershagan Training and Activity Centre, Stange, Hedmark, Norway <cecilieflo@hotmail.com>

${ }^{\mathrm{i}}$ The Special Pedagogical Team, Gran, Oppland, Norway <lise.nes@online.no>

${ }^{j}$ Statped, Department of Speech and Language Disorders, Bergen, Norway <ragnhild.r.heitmann@statped.no>

k Trondheim, Norway <hbknidaros@gmail.com>

${ }^{1}$ Unknown

< sofia.nilsson@med.lu.se >

${ }^{\mathrm{m}}$ Speech-Language Pathology, Helsingborg Hospital, Helsingborg, Sweden <tobias.wetterling@skane.se>

${ }^{\mathrm{n}}$ Lund University, Lund, Sweden <cecilia.lundstrom@med.lu.se>

${ }^{\mathrm{o}}$ Wicklow Primary Healthcare Centre, Knockrobin, Wicklow Town, Ireland < ciaraann.daly@hse.ie >

$\mathrm{p}$ Trinity College, Dublin, Ireland <mleahy@tcd.ie>

${ }^{\mathrm{q}}$ Berkshire Healthcare NHS Foundation Trust, Thatcham, UK <laila_mallah@hotmail.co.uk>

${ }^{\mathrm{r}}$ University of Reading, Reading, UK $<$ d.ward@reading.ac.uk>

${ }^{\mathrm{s}}$ University of York, York, UK <mw700@york.ac.uk> 

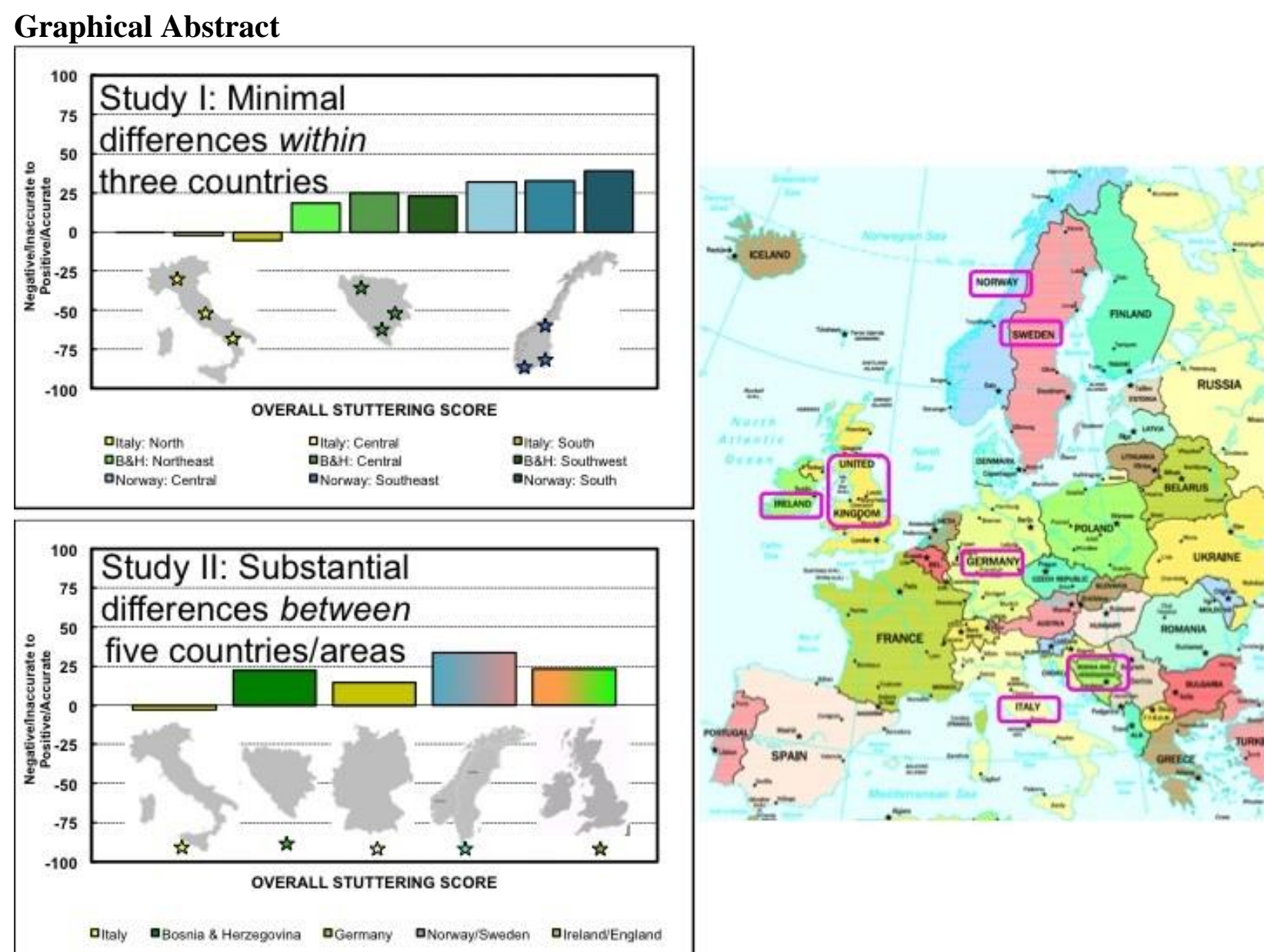


\section{HIGHLIGHTS}

Stuttering attitudes in Europe and North America have been assumed to be quite uniform.

Public attitudes toward stuttering within three European countries were remarkably similar.

Public stuttering attitudes between five European countries/regions were quite different.

Expected demographic variables did not predict the differences between countries/regions.

Yet-to-be discovered national variables likely are important in country/region differences. 
Abstract: Introduction. Epidemiological research methods have been shown to be useful in determining factors that might predict commonly reported negative public attitudes toward stuttering. Previous research has suggested that stuttering attitudes of respondents from North America and Europe (i.e., "The West"), though characterized by stereotypes and potential stigma, are more positive than those from several other regions of the world. This inference assumes that public attitudes within various regions characterized by "The West" are similar. Purpose. This study aimed to determine the extent to which public stuttering attitudes are similar or different both within regions of three different European countries and between or among five different European countries or similar geographic areas. It also aimed to compare these European attitudes to attitudes from 135 samples around the world using a standard measure. Material and Methods. Using convenience sampling, 1111 adult respondents from eight different investigations completed the Public Opinion Survey of Human Attributes-Stuttering (POSHA-S) in the dominant language of each country or area. In Study I, the authors compared attitudes within three different regions of Bosnia \& Herzegovina, Italy, and Norway. In Study II, the authors compared attitudes between combined samples from Bosnia \& Herzegovina, Italy, and Norway (with additional respondents from Sweden), and two other samples, one from Germany and the other from Ireland and England. Results. Attitudes of adults from the three samples within Bosnia \& Herzegovina, Italy, and Norway were remarkably similar. By contrast, attitudes between the five different countries or area were quite dramatically different. Demographic variables on the POSHA-S did not predict the rank order of these between-country/area differences. Compared to the POSHA-S worldwide database, European attitudes ranged from less positive than average (i.e., Italians) to more positive than average (i.e., Norwegians and Swedes). Conclusion. Factors related to national identity appear to play a significant role in differences in public attitudes in Europe and should be explored in future research.

Keywords: POSHA-S; Stuttering; Public Attitudes; Europe; Within-country, Between-country 


\section{INTRODUCTION}

Scientific inquiry into public attitudes toward stuttering (beliefs, reactions, or perceptions regarding stuttering) began four decades ago in the USA with the work of Dean Williams and his colleagues (Woods \& Williams, 1971; 1976; Yairi \& Williams, 1970) and has continued steadily for a generation. Hundreds of studies have converged on the conclusion that the public holds attitudes about people who stutter that are biased, negative, stigmatizing, or discriminatory (e.g., Bloodstein \& Bernstein Ratner, 2008; Boyle \& Blood, 2015; Manning, 2010; Shapiro, 2011). The rationale for this research has been (a) to document differences in public attitudes toward stuttering around the world in order to identify factors responsible for differences observed and (b) to inform efforts to mitigate negative attitudes toward people who stutter.

\subsection{Geographic Studies of Stuttering Attitudes}

St. Louis (2015a) called for additional studies that could identify variables that might be responsible for differences in public attitudes toward stuttering in various countries or geographic regions. Research has shown that, despite consistent evidence of ignorance about or negative attitudes toward stuttering in so-called Western cultures ("the West"), i.e., North America, Western Europe and Australia, Western public attitudes are typically more positive than in other parts of the world (e.g., Przepiórka, Błachnio, St. Louis, \& Wozniak, 2013; St. Louis, 2012a; St. Louis, Sønsterud, Carlo, Heitmann, \& Kvenseth, 2014; St. Louis, Przepiórka, et al., 2014). For example, non-Western attitudes were found to be less positive than Western attitudes in the Middle East (Abdalla \& St. Louis, 2012, 2014; Alshdifat, Mayo, \& St. Louis, 2013; Özdemir et al., 2011a; Özdemir, St. Louis, \& Topbaş, 2011b), South America (St. Louis, et al., 2005), Asia (Ip, St. Louis, Myers, \& An Xue, 2012), and Africa (St. Louis \& Roberts, 
2010). Nevertheless, there have been exceptions to this generalization (e.g., Elsiddig et al., Haynes, Atwood, \& St. Louis, 2015; St. Louis, Filatova et al., 2011; St. Louis, Sønsterud, et al., 2014; ). In his discussion of the epidemiology of public attitudes toward stuttering, St. Louis (2015a) drew attention to this fact and called for additional exploration of the effects of living in specific geographic regions on public attitudes.

Several investigators have advanced the notion that North American and European stuttering attitudes are similar (e.g., Daly \& Leahy, 2014; Preus, 1981; Valente, Jesus, Leahy, \& St. Louis, 2014). Before definitive studies confirming that living in different parts of the world are associated with better or worse public attitudes toward stuttering than others, it must be shown that attitudes within various regions are reasonably similar. Thus, if the aforementioned assumption that Western attitudes are most positive is to be supported, it must be shown that attitudes in "The West" (i.e. within Europe and between Europe and North America) are similar.

Almost all of the aforementioned studies have sought to document differences between countries. Only a few investigations permit comparisons across two or three countries (e.g., de Britto, Pereira, Rossi, \& Van Borsel, 2008; St. Louis, Abdalla, Burgess, \& Kuhn, 2015; St. Louis, LeMasters, \& Poormohammad, 2015; St. Louis, Przepiorka, et al., 2014; Van Borsel, Verniers, \& Bouvry, 1999; Xing Ming, Jing, Yi Wen, \& Van Borsel, 2001). To our knowledge, only one study has systematically investigated public attitudes toward stuttering within an entire country, i.e., Portugal (Valente et al., 2014); however, a few studies—or groups of studiespermit comparisons of differences within countries, e.g., among Native American adults (Indians) in the USA (Beste-Guldborg, St. Louis \& Campanale, 2015), adults in Turkey (Maviş, St. Louis, Özdemir, \& Toğram, 2013), and adults in Poland (Błachnio, Przepiórka, St. Louis, Węsierska, \& Węsierska, 2015). In these studies, greater similarities have been reported than 
differences from divergent regions of the country. Exceptions have also been reported, however. For example, one island region of Portugal held more positive attitudes than most of the other regions of the country.

\subsection{Purposes}

Seeking to provide data relative to differences within and between European countries the current study drew together investigations, or parts thereof, of public attitudes toward stuttering. Two separate analyses were carried out (Study I and Study II) that addressed the following research questions.

(1) To what extent are there regional differences in public attitudes toward stuttering within three Western European countries? (Study I)

(2) To what extent are there differences in public attitudes toward stuttering among five Western European countries? (Study II)

(3) To what extent are samples of public attitudes both within and between countries similar to measured attitudes around the world? (Studies I and II)

(4) If substantial differences exist among the five countries, what demographic or other variables would predict the rank order of the ratings for the countries? (Study II)

\section{STUDY I: WITHIN-COUNTRY COMPARISONS}

\subsection{Method I}

The reader is reminded that, throughout this article, country names are used to refer to various samples for sake of readability but refer only to the samples in question or others nearly identical to them. They emphatically do not refer to all persons in the countries or regions.

\subsubsection{The instrument: Public Opinion Survey of Human Attributes-Stuttering (POSHA-S)}

A few initiatives in the literature have compared attitudes toward stuttering in different 
populations, but the most ambitious initiative to do so has been the International Project on Attitudes Toward Human Attributes (IPATHA) (St. Louis, 2011a). Its primary achievement has been to develop and make available to researchers a standard instrument that can be used around the world, the Public Opinion Survey of Human Attributes-Stuttering (POSHA-S) (St. Louis, 2005, 2011a, 2011b, 2012b, 2015b; St. Louis, Lubker, Yaruss, Adkins, \& Pill, 2008).

The POSHA-S is a written survey instrument containing three sections: (a) a demographic section, (b) a general section that compares stuttering to four other human attributes, and (c) a detailed stuttering section. The demographic section asks respondents for the following information: sex, marital and parental status, educational, occupation, native language and other languages known, income, race, and religion. It also asks respondents to self-rate their health (physical and mental) and abilities (to learn new things and to speak). Additionally, respondents self-rate 12 life priorities (e.g., being safe and secure or helping the less fortunate).

The purpose of the general section is to place the attribute of stuttering into perspective by comparing it on four ratings to four other "anchor" attributes ranging from positive (intelligent), to neutral (left handed), to negative (obesity and mental illness). This enhances comparisons between samples wherein stuttering attitudes might be similar but attitudes toward the other anchor attributes might be quite different. Respondents rate their overall impression of each attribute, the degree they want to be/have it, how much they know about it, and who they know with it. The last item generates a score for experience with stuttering.

The detailed stuttering section has 35 items that ask about stuttering's causes, traits or personality of people who stutter, who should help them, and their life potential (e.g., "People who stutter can lead normal lives"). Items also relate to one's knowledge and source of knowledge regarding stuttering and what the respondent might do in a conversation (e.g., "Tell 
the person to "slow down" or "relax)." In scoring, the stuttering items are clustered into components and components into two subscores, i.e., Beliefs about—and Self Reactions topeople who stutter. Beliefs items are external to the respondent while Self Reactions items are internal to the respondent or involve him or her in some way. The mean of these two stuttering subscores is the Overall Stuttering Score (OSS).

All of the items, components, subscores, and OSS are shown in Supplementary Datasets $\mathrm{A} 2$ and $\mathrm{B} 2$. The means for the various ratings are converted to a -100 to +100 scale, where 0 equals a neutral rating. Ratings on some of the items are inverted so that higher mean ratings uniformly reflect "better" attitudes, i.e., more accurate or sensitive beliefs and reactions based on the extant research. Lower ratings reflect "worse" attitudes.

Components, subscores, and the OSS are typically depicted in radial graphs that compare specific samples to the highest sample mean, lowest sample mean, and median of all the sample means included in the POSHA-S database (St. Louis, 2011, 2015a). OSS values are shown in the boxes at the lower right (See Figures 1-4). In these radial graphs, more positive attitudes are closer to the periphery while more negative attitudes are closer to the center.

Sociometric and practical properties of the POSHA-S have been investigated extensively and found to be satisfactory, i.e., reliability (St. Louis, Lubker, Yaruss, \& Aliveto, 2009; St. Louis, 2012b), construct and discriminant validity (St. Louis, Reichel, Yaruss, \& Lubker, 2009; St. Louis, Williams, Ware, Guendouzi, \& Reichel, 2014), and internal consistency (Al-Khaledi, Lincoln, McCabe, Packman, \& Alshatti, 2009; St. Louis, 2012b). The POSHA-S has been shown to be user friendly (St. Louis, 2012b; St. Louis et al., 2008), translatable to other languages with equivalent results (St. Louis \& Roberts, 2013), and amenable to either paper or online administration (St. Louis, 2012a). Expected differences in attitudes have resulted from 
convenience versus probability sampling (Özdemir et al., 2011a). Importantly, however, no differences have been observed when comparing ratings of an undefined hypothetical person who stutters (the standard administration) to ratings following a definition of stuttering. This is important to the current study, as we combine data using both administration techniques. were observed in POSHA-S ratings when the standard, undefined, hypothetical person who stutters are compared with ratings following a lay definition of stuttering (St. Louis, Filatova, et al., 2011; St. Louis, Sønsterud, et al., 2014).

Data from numerous previous studies utilizing the POSHA-S have been entered into a database, making it is possible to compare individual respondent samples with those from other samples around the world (St. Louis, 2011b). Respondents in this study are compared to 135 samples containing 10,657 respondents that represent 39 countries and 25 languages (as of November, 2015). Excluded were samples of speech-language pathology students or practitioners, samples consisting entirely of people who stutter, and samples whose respondents rated earlier versions of the POSHA-S on different rating scales.

The English version of the POSHA-S was translated by co-authors into BosnianCroatian-Serbian, into Italian, and into Norwegian for this within-country study and into German for the between-country study. As reported in several investigations (e.g., St. Louis \& Roberts, 2010), each initial translated version was back-translated to English by a knowledgeable person unfamiliar with the study and then compared with the original English version to assure that they were equivalent in meaning, even if the wording might differ slightly.

\subsubsection{Demographics I}

A total of 669 adults were respondents in the within-country study taken from three independent investigations: 283 from Bosnia \& Herzegovina in the Balkan area of Europe 
(Junuzović-Žunić, personal communication), 300 from Italy in the Mediterranean area (Tomaiuloi, DelGado, Caparelli, \& St. Louis, 2013), and 86 from Norway in the Scandinavian area (St. Louis, Sønsterud, et al., 2014; St. Louis, Sønsterud, Heitmann, Kvenseth, Flobakk, \& Helmen, 2012). Importantly, investigators in each of these three countries designed their studies to sample in three different regions of the country. Their purpose was to look for similarities or differences from region to region.

In Bosnia \& Herzegovina (B\&H), undergraduate speech-language pathology and audiology students from the University of Tuzla who lived in different regions of Bosnia \& Herzegovina (which includes the Federation of B\&H and the Republic of Srpska) handed out questionnaires to colleagues, friends, family members who were not speech-language pathologists (SLPs). Investigators focused on three regions: the northeastern region (the Republic of Srpska), the central region (primarily in and around the cities Sarajevo and Zenica), and the southwestern region (primarily in and around the cities of Mostar and Livno). These were selected to represent, respectively, high concentrations of Orthodox Christians, Muslims, and Catholic Christians, although all three religions were represented in all three regions.

Similarly in Italy, coauthors and others who assisted them recruited non-SLP adults from the northern region in most of the northern provinces (including Emilia Romagna, Liguria, Lombardia, Piemonte, Veneto, and Friuli Venezia Giulia), the central region (including Lazio, Umbria, Molise, Abruzzo, and Marche), and the southern regions (including Calabria, Sicilia [Sicily], Puglia, Campania, and Basilicata). The selections were targeted to represent large geographic differences in the country (Tomaiuoli, Del Gado, \& Caparelli, 2013).

The Norwegian samples were obtained from parallel samples that were carried out somewhat differently than the former two since they were from a study of attitudes and 
identification of cluttering and stuttering (St. Louis et al., 2012; St. Louis, Sønsterud, et al., 2014). The central Trondheim and southern Oslo region samples consisted of adults with the only constraint that they could not be speech-language pathologists (SLPs) or SLP students, while the southeastern Oppland and Hedmark region respondents were school teachers (none of whom were SLPs). In the central region, respondents filled out an adapted POSHA-S that asked the same questions as the standard POSHA-S version, except that the order of items was slightly altered, and these were followed by questions asking respondents to identify any children or adults they knew who stuttered. The other notable difference was that a lay definition of stuttering was provided at the outset ${ }^{1}$. Respondents in the southern region were asked the same questions, but also parallel attitude and identification questions about cluttering, again, after lay definitions were provided. These comprised the stuttering parts of the aforementioned study that was designed to disambiguate attitudes toward stuttering from attitudes toward cluttering (c.f. St. Louis, Filatova, et al., 2011) wherein a third group (not reported here) from the Bergen region of Norway received the cluttering items only (St. Louis, Sønsterud, et al., 2014). The classroom teachers in the southeastern region and reacted, like the central group, to both stuttering and cluttering (with definitions provided); however, their attitudes were not included in the St. Louis, Sønsterud, et al., (2014) report. ${ }^{2}$

Including teachers in the public sample is justified by extant data. St. Louis (in press) summarized POSHA-S-generated attitudes from 23 different samples of teachers representing 15 different countries. Their mean Obesity/Mental Illness subscore of -31 , Beliefs subscore of 28, Self Reactions subscore of 5, and OSS of 17 were very similar to the public database values of 35, 33, 2, and 17, respectively (shown in Supplementary Dataset A-2). Silva, Leal, Correia, Valente, and St. Louis (in press) and Valente et al. (2014) revealed that teacher and non-teacher 
samples in Portugal were also quite closely aligned. Similarly, using an earlier POSHA-S database, Arnold, Li and Goltl (2015) showed teacher Beliefs to be no different than those of non-teachers, and Li and Arnold (2015) showed a slight difference on only one of four Self Reaction components.

POSHA-S return rates for each of these subgroups were based on the number of questionnaires received from each region in the three countries divided by the best estimate of the number handed out. Regional return rates for Bosnia \& Herzegovina ranged from $86 \%$ to 93\% (comprising 77, 122, and 84 respondents), for Italy, from 69\% to 77\% (103, 112, and 116 respondents in each region but with 100 analyzed from each region), and for Norway, 66\% to $92 \%$ 20, 43, and 23 respondents).

\subsubsection{Data Analyses I}

To estimate the extent to which the results of the three regions within the three countries are typical or atypical of other adult stuttering attitudes around the world, results for the three countries were compared to the POSHA-S database graphically in terms of the highest, lowest, and median sample means observed in the 135 samples heretofore analyzed in the database (see section 1.1.3.). To determine the significance of differences observed between each region, we applied independent $t$ tests between the three pair-wise contrasts for each of the three regions, e.g., in Italy, north vs. central, north vs. south, and central vs south. The Bonferroni correction of $\mathrm{p} \leq .00417(.05 / 12)$ was applied. Dividing .05 by 12 was carried out with the first experimental version of the POSHA-S based on the fact that the mean number of items per prompt was 12 (St. Louis et al., 2008). Subsequently, St. Louis (2012b) justified the use of this same alpha level, even when the number of items per prompt was reduced, by showing that it provided a desired conservative approach for identifying $P O S H A-S$ differences but one that struck an optimal 
balance of reducing the probability of Type I errors (reporting differences as significant when they are not) while simultaneously reducing the likelihood of Type II errors as well (reporting no significant difference when in fact one does exist) (Fagerland, 2012; Stonehouse \& Forrester, 1998). This alpha level has been used in the majority of the POSHA-S studies cited in this paper. Cohen's $d$ effect sizes (Cohen, 1988) were then calculated for significant differences.

\subsection{Results I}

\subsubsection{Respondent characteristics $I$.}

Supplementary Dataset A-1 provides a detailed summary of demographic characteristics of respondents within each of the nine regions. Mean ages for Bosnian \& Herzegovinians differed only by $3.7 \mathrm{yr}$, and the age ranges from Italy, even less, i.e., $1.8 \mathrm{yr}$. The Norwegian groups were more variant in age, i.e., from 33 to 48 yr, or 15.1 yr. Respondents in all nine subgroups reported completing 13-15 years of education. In all but the central Italian region, more females than males were surveyed. Half of the central Norwegian subgroup reported being students; thus, they were predictably younger with smaller percentages reporting being married or parents than any of the other eight subgroups. Otherwise the samples were not remarkably different with respect to marital status, parenthood, or work status.

Income on the POSHA-S is not determined by specific monetary (e.g., dollar) amounts; instead it is relative to the rated incomes of one's friends and family as well as all the people in one's country. Converted to the -100 to +100 scale, the database average for both ratings is virtually in the middle, i.e., -1 . Respondents from Bosnia \& Herzegovina reported below average relative incomes, Italians, about average incomes, and Norwegians, above average incomes (except the central subgroup, who were average).

Race and religion were not included in the Norwegian questionnaires (mandated by the 
human subjects protection committee), but $95-100 \%$ of the other six groups reported variants of Caucasian race. In all three Italian regions, about $85 \%$ of the Italians reported being Catholics with virtually no Orthodox or Muslim respondents, but the respondents in Bosnia \& Herzegovina, as expected, had highly variable religious identities. Seventy-six percent of the northeastern respondents were Orthodox, $84 \%$ of the central respondents were Muslim, and $98 \%$ of the southwestern respondents were Catholic. Native languages were what would be expected. It should be noted that Bosnia \& Herzegovina respondents listed numerous different combinations of Bosnian, Croatian, or Serbian as their native language. These constitute a diasystem, or origin from one language, but with three different names and three different standards. In spite of their differences, speakers of the Bosnian, Croatian, and Serbian languages can understand and communicate with one another.

Virtually none of the respondents regarded themselves as a person who stutters $(0 \%-1 \%)$ or mentally ill (0\%-2\%), and few thought themselves to be obese (0\%-6\%). Only $12 \%$ to $26 \%$ regarded themselves as intelligent. More than half $(51 \%-57 \%)$ of the Italians reported not knowing anyone who stutters compared to $20 \%-30 \%$ of the Norwegians and $13 \%-16 \%$ of the Bosnian \& Herzegovinians. From 22\%-35\% of the subgroups from Bosnia \& Herzegovina and Italy reported knowing no one with mental illness, compared to fewer Norwegians (13\%-16\%). Results for the health, abilities, and life priorities were not remarkable or notably different for any of the nine subgroups.

\subsubsection{Comparisons: POSHA-S Database, Graphic Profiles, and Within Country Ratings I}

Components and subscores are displayed in radial graphs for Bosnia \& Herzegovina, Italy, and Norway in Figures 1, 2, and 3, respectively. (Color figures are provided in the Supplemental materials.) These provide a visual depiction of the degree to which the stuttering 
attitudes in each region differed from the highest, lowest, and median (average) sample mean rating (small dotted line) derived from 135 sample means in the POSHA-S database (as of November, 2015). The large and rapidly growing database is sufficiently robust that individual samples added since 2011 have resulted in only very small changes to these benchmarks.

It is apparent that the three samples from Bosnia \& Herzegovina were close to or slightly above the median tracing (Figure 1), suggesting that the respondents held roughly typical, or slightly better attitudes than the range of unselected adults sampled around the world. By contrast, the samples from Italy were almost uniformly below the median tracing (Figure 2), representing more negative than average public attitudes. Also, by contrast, the Norwegian samples held attitudes that were mostly and uniformly above the median tracing (Figure 3), indicative of more positive than average public attitudes. In fact, for the Traits/Personality and Cause components, their ratings were close to the highest observed to date.

$$
\text { (Place Figures 1, 2, and } 3 \text { about here.) }
$$

Comparing the tracings in each of the radial graphs, it is clearly evident that the three profiles within each of the three regions of Bosnia \& Herzegovina, Italy, and Norway were very similar. This indicates that whatever influenced ratings for one region of each country appeared to have very similar influence in the other two regions. The means and standard deviations of each of the POSHA-S items, components, subscores, and OSS for the three regions of each country alongside the POSHA-S database median are listed in Supplementary Dataset A-2.

Percentages of significant differences for the pair-wise within-country $t$ test comparisons, as well as the mean Cohen's $d$ effect sizes of those that were significant, are summarized in Table 1. St. Louis (2012b) reported that percentages of significant differences from $t$ test pairwise contrasts for the 60 POSHA-S ratings which were in the range of $0-5 \%$ reflected little or no 
difference between samples. Percentages in the 5-10\% range signified small differences, in the 10-30\% range, moderate differences, and beyond 30\%, large differences. Accordingly, the northeast and southwest regions of Bosnia \& Herzegovina held very similar attitudes toward stuttering (only 1 or $2 \%$ of 60 differences being significant), while the central region had marginally better attitudes overall than either of them (10\% and 7\%). The few differences that were significant yielded Cohen's $d$ effect sizes from .43 to .53 or “moderate” (Cohen, 1988). Although there were no differences in Beliefs and its components, the central region of Bosnia \& Herzegovina held more positive Social Distance/Sympathy component attitudes (44 versus 25 and 33 for the northeast and southwest regions, respectively). Similarly, the northern Italian region differed from the central and southern regions on only one $P O S H A-S$ rating (2\%), i.e., for the "amount known" about stuttering, the northern region rated -33 while the central region rated -51 , and for "filling in words," northern respondents' mean rating was 32 compared to southern respondents' ratings of -14 . The central and southern Italian regions did not differ significantly on any ratings $(0 \%)$. In Norway, the only significant difference was for the source of stuttering knowledge from "school," where the teachers in the southeast region rated this item much higher (43) than the general public from southern region (-77), with a "very large" effect size (1.48). Table 1 Percentages of statistically significant pair-wise comparisons between the three different regions of three European countries (Bosnia-Herzegovina, Italy, and Norway) for all 60 POSHA-S mean ratings (including 35 items, 11 components, 3 subscores, and the Overall Stuttering Score). The mean Cohen's d effect sizes for these significant pair-wise comparisons are shown in parentheses. 


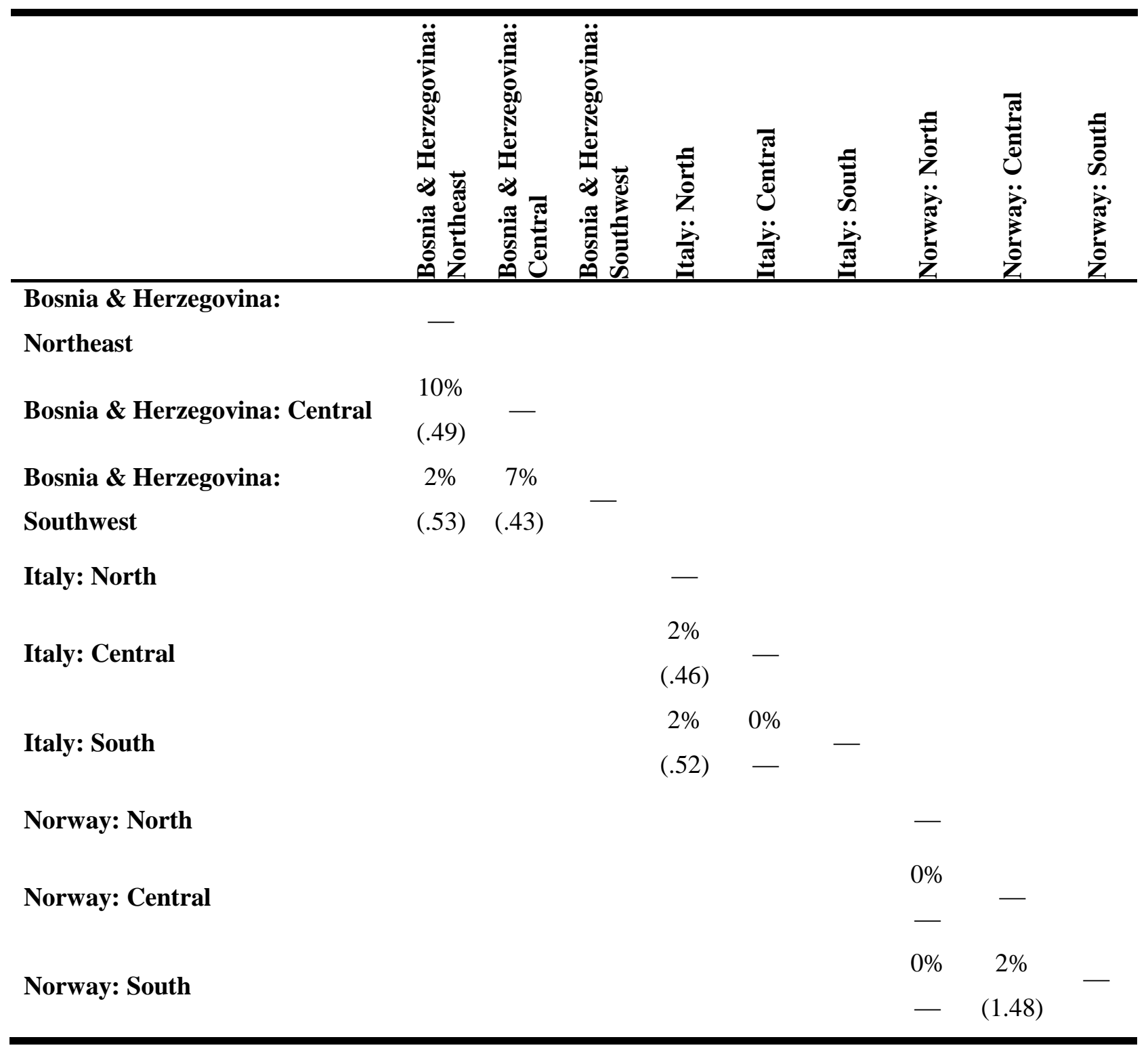

\subsubsection{Rating Variability Within Countries I}

Another way to ascertain differences between each of the three regions in the three countries is to determine the relative variability among $P O S H A-S$ mean ratings for each of 60 POSHA-S ratings (items, components, subscores, and OSS). For example, the absolute differences in scores (regardless of plus or minus values) between the northern versus central, northern versus southern, and central versus southern regions of Italy were summed for each rating. Next, these sums were divided by 3 to determine the average region difference, or 
variability, on any $P O S H A-S$ rating from one region to the next. The same procedure was carried out for Bosnia \& Herzegovina and for Norway. Rating variability for all three regions within all three countries ranged from 3.7 to 4.9 units of the 201-item scale for the OSS, 10.0 to 13.0 units for the Beliefs subscore, 9.8 to 15.5 units for the Self Reactions subscore, and 3.8 to 8.3 units for the Obesity/Mental Illness subscore. These small numbers represent within-country differences of only 4 to 15 units on the scale and confirm the aforementioned similarities among the three regions for each country.

\section{STUDY II: BETWEEN-COUNTRY COMPARISONS}

\subsection{Method II}

\subsubsection{Demographics II}

Five different countries or areas of Europe were sampled in Study II. For three of them, the three regional groups of respondents in Study I were combined within each country since that study clearly indicated that there were few or no within-country regional differences. The combined Bosnia \& Herzegovina data $(\mathrm{n}=283)$ represented the Balkan area, and the combined Italy data $(n=300)$ represented the Mediterranean area. Since the Norway sample, representing the Scandinavian area, contained only 86 respondents, it was augmented by a sample of 42 nonimmigrant respondents from Sweden who were part of another study (Nilson \& Wetterling, 2013). The Swedish study used the POSHA-S in the standard format, i.e., without a written definition of stuttering as had characterized the Norwegian samples. The Swedish study employed two different sampling procedures. For some of the data, it utilized a probability sampling procedure similar to that of Özdemir et al, 2011a, 2011b primarily in the southern region of the country using paper-and-pencil POSHA-Ss handed out in randomly selected schools with arrangements for children to take questionnaires home for one of their parents to 
complete. Because that did not yield enough respondents, the authors sampled respondents in the capital of Stockholm and two other widely distant cities with an online POSHA-S. The combined Scandinavian area sample contained 128 respondents. A sample of 251 persons from Germany was added to represent the central area of Europe (Theiling, 2013). Theiling's study compared SLP versus non-SLP respondents on the POSHA-S, but only the non-SLP public sample was used here. A majority of the German respondents (58\%) lived in the western part of the country, but $12 \%$ to $15 \%$ of the sample lived, respectively, in the northern, eastern, and southern areas as well. Finally, three samples were combined from Ireland and England to represent Englishspeaking, island nations west of the European mainland. Thirty-seven respondents who were chosen using a quasi-probability sampling scheme from the southern area in an around Cork, Ireland filled out the POSHA-S (Daly \& Leahy, 2014). Again, since the Ireland sample was comparatively quite small, we augmented it with two convenience samples of non-SLP college students from England. The first consisted of 62 respondents from the Reading and Oxfordshire area of England who were part of study comparing stuttering attitudes of students in the UK and Syria (Tyrrell, 2011). The second consisted of 50 English students from the Leicestershire region who participated in a study that investigated the effects of information on stuttering or ADHD on attitudes of students from the UK and Poland (Węsierska \& St. Louis, 2014). These 50 students were a control group who did not receive information about ADHD or stuttering. The combined Ireland/England sample consisted of 149 respondents. Adding all five country/area samples resulted in a total of 1111 respondents.

We carried out the following procedures to justify the combination of different samples for Norway/Sweden and Ireland/England. Following similar procedures as were described for regional comparisons in Study I, the Swedish sample was compared to the combined Norwegian 
sample and the three Irish or English samples were compared to one another using pair-wise $t$ tests and percentage of summary score variability. The percentage of significant differences between these samples were somewhat greater than in Study I but, as will be seen below, considerably smaller than between the five countries/areas . The Norwegians had slightly more positive attitudes than the Swedes, with 12\% (7/60) of pair-wise comparisons reaching statistical significance. Twenty percent (12/60) of the POSHA-S comparisons between the Ireland vs. England Oxfordshire region ratings were significant. Also significant were 8\% (5/60) of the Ireland vs. England Leicestershire region and 10\% (6/60) of the Oxfordshire vs. Leicestershire comparisons. OSS means between the three Irish/English samples varied by 4.6 units of the total -100 to +100 scale, Beliefs by 22.2 units, Self Reactions by 13.9 units, and Obesity/Mental Illness by 12.8 units. Between the Norwegian and Swedish samples, variability for OSS, Beliefs, Self Reactions, and Obesity/Mental Illness was 3.5, 13.3, 14.1, and 16.3 units, respectively. These variability percentages (representing 3 to 22 scale units) were, again, somewhat greater than between each of the three regions for the three countries in Study I, yet much smaller than between the five countries/areas (see below). We concluded that although the subgroups in the Scandinavian and Irish/English samples were not completely uniform, neither were they widely different. The increased statistical power obtained by increasing sample sizes was judged to outweigh slight disadvantages of combining respondents from different countries.

\subsubsection{Data Analyses II}

Virtually identical analyses were applied to the POSHA-S results as for Study I. Results for the five countries/areas were compared to the $P O S H A-S$ database graphically in terms of the highest, lowest, and median sample values observed in the POSHA-S database. All pair-wise comparisons were run between country/areas, comprising 10 different between-country pairings. 
The percentages of these comparisons significant for each of the POSHA-S ratings were calculated as well. In addition in Study II, rank-order analyses, described in section 3.2.3., were carried out.

\subsection{Results II}

\subsubsection{Respondent characteristics II.}

Complete demographic data are provided in Supplementary Dataset B-1. In all cases, respondents filled out paper-and-pencil versions of the English or translated versions of the POSHA-S. Return rates ranged from $16 \%$ to $91 \%$ (with calculations explained in footnotes after Supplementary Dataset B-1). With the exception of the Irish/English sample, mean ages of the samples ranged from 37 to $42 \mathrm{yr}$. These compare favorably to the median age of samples in the POSHA-S database of $37.3 \mathrm{yr}$. In the English-speaking sample, the Irish mean age was $32 \mathrm{yr}$, but the mean was tempered by the two English student samples with mean ages of 23 and $21 \mathrm{yr}$. Approximately $40 \%$ of the Germans also reported student status; the students' ages were comparable to other university students, but the nonstudents were older, generating a mean age of $37 \mathrm{yr}$. Education levels were roughly equivalent for the five samples at 13-14 $\mathrm{yr}$ and close to the database median of $14.5 \mathrm{yr}$. Also, except for the Irish-English group containing a majority of students, the groups were not markedly different for percentages of respondents who were married, parents, or working. Relative incomes were lowest (-9) for Bosnia \& Herzegovina, average for Italy (1), somewhat above average for Ireland/England (7), and considerably above average for Scandinavia (14) and Germany (15). Native languages were as expected but with the largest percentage (7\%) of other native language speakers in the Irish/English sample. Additional languages known by respondents was not asked of the Norwegians; yet, multilingual percentages of the other countries ranged from $36 \%$ for Ireland/England (the database average) 
to $98 \%$ for Sweden. Self-identification as stuttering and mentally ill was uniformly low (0\%$2 \%$ ). Self-identified obesity was somewhat higher and closer to the database average of $5.6 \%$, i.e., the Germans reported 7\%, and the four other countries/areas reported 4-5\%. The Italians and Irish/English samples were most likely to report knowing no one who stuttered, 54\% and 44\%, respectively, while of the five areas, Bosnian \& Herzegovinians were least likely to (14\%).

Whereas the percentages of significant pair-wise differences for self-ratings of physical health, mental health and ability to learn were $20-30 \%$, the percentage for speaking ability was $60 \%$, with Italians and Germans (at 47 and 53, respectively) or lower than the database average of 62. Given that these public respondents were typical, differences are likely indicative of cultural or national differences rather than actual speaking ability. For rated priorities, "helping the less fortunate" was quite different (80\% significant differences, with the Germans [29] and Irish/English [23] rating it the lowest), as was "practicing one's religion" (70\% significant differences, with the German [-28], Scandinavian [-39], and Irish/English [-43] respondents according it lower priority than the Bosnian \& Herzegovinian [31] or Italian [6] respondents). Earning money was accorded lower than average priority (database median $=56$ ) for the Italians (36), Scandinavians (44), and — to a smaller extent—Germans (54).

\subsubsection{Comparisons: POSHA-S Database, Graphic Profiles, and Between Country Ratings II}

Compared to the similarities in the three sample tracings for the Study I within-country comparisons in Figures 1-3, Figure 4 illustrates marked differences among the five countries/areas in Study II. Scandinavian attitudes were the most positive and Italian attitudes were the least positive. German tracings most often appear in the middle of the five countries/areas and also closely mirror the median ratings from the POSHA-S database. Bosnian \& Herzegovinian and Irish/English attitudes were somewhat above average. Comparatively, 
these European means are well between the highest and lowest observed so far. As with most other samples, Obesity and Mental Illness ratings are very low.

(Place Figure 4 about here.)

Supplementary Dataset B-2 lists all mean ratings and standard deviations of POSHA-S items, components, subscores, and OSSs. Consistent with results from the within-country analyses in Study I, even with the addition of a Swedish component with slightly less positive attitudes, the Scandinavian respondents had the most positive OSSs toward stuttering (34), followed by combined data for the Bosnian \& Herzegovinians (23), and then by the Irish and English (23), the Germans (15), and the combined Italians (-3). The POSHA-S database median (as of November, 2015) was 17. Ratings for the Beliefs subscores, from most to least positive, were: Scandinavians (57), Irish/English respondents (45), Germans (34), database median (32), Bosnian \& Herzegovinians (32), and Italians (10). The Self Reactions subscores had a different rank order: Bosnian \& Herzegovinians (13), Scandinavians (10), Irish/English (2), database median (1), Germans (-4), and Italians (-16). As observed in other studies, results for the Obesity/Mental Illness subscore were quite negative as follows: Bosnia \& Herzegovina (-22), Ireland/England (-33), database median (-35), Germany (-39), Scandinavia (-42), and Italy (-46).

The following supporting examples — and exceptions - to these summary ratings are noteworthy. Scandinavians had dramatically more positive ratings for people who stutter not being shy and fearful (64) versus a range of -45 to -5 for the other countries/areas. The Scandinavians (70), and to a reduced extent the Irish/English (24), were less likely than average (database median $=-15$ ) to be concerned if a sibling stuttered. By contrast, the Scandinavians were least likely to want to have stuttering ( -70 [the database median as well] versus -58 to -69$)$. Italians were most likely to advise a stuttering person to "Slow down" or "Relax" ( 1 versus 23 to 
69 with a database median of 2). Bosnian \& Herzegovinians, Germans, and Italians were much less likely to reject the notion that stuttering is caused by a very frightening event than the Scandinavians or Irish/English (-61 to -9 versus 29 to 47). Bosnian \& Herzegovinians were less likely to reject that stuttering is caused by an act of God than the other four samples ( 9 versus 67 to 94). Germans were much less likely than the other Europeans to believe that stuttering persons can do any job they want (-22 versus -5 to 61 ), and although generally holding positive attitudes, the Scandinavians were least likely to believe that stutterers should hold jobs requiring good judgment (-18 versus 8 to 59). Respondents from Bosnia \& Herzegovina had consistently the best attitudes on three items in the Social Distance/Sympathy component, i.e., feeling comfortable or relaxed around stuttering ( 84 versus -32 to 44 ) and rejecting both feeling pity ( 82 versus -8 to 16 ) and impatience (92 versus -32 to 44 ). The Bosnian \& Herzegovinians had the highest or second highest most positive scores for all Obesity/Mental Illness ratings (-22 compared to -46 to -33 for the other country/area respondents), indicating that there were smaller differences between their stuttering and other ratings for negative attributes.

The question arises, “Are these differences between countries significant?" The answer is clearly affirmative. Supplementary Dataset B-2 lists percentages of the 10 pair-wise contrasts that were statistically significant for each mean rating. Table 2 shows the means for the 60 $P O S H A-S$ ratings as well as the average effect sizes. The most frequent significant differences, which occurred between attitude ratings of Norway/Sweden versus Italy (77\%), were not surprising since these two samples held, respectively, the most and least positive attitudes. The fewest significant differences (42\%) were observed between Germany and Ireland/England. Effect sizes ranged from .49 ("moderate") to .81 ("large"). Applying the aforementioned guidelines advanced by St. Louis (2012b), the differences between any pair of the five European 
countries/area were among the largest observed in any POSHA-S investigation to date (St. Louis, 2015a). Juxtaposing these results with those in Table 1 for the within-country comparisons, the take-away message is clear. Measured attitudes toward stuttering between the five countries or areas selected for this study indicate that attitudes are affected by some factors related to living in different countries.

Table 2

Percentages of statistically significant pair-wise comparisons between the five countries or areas (Bosnia-Herzegovina, Italy, Germany, Norway/Sweden, and Ireland/England) for all 60 POSHA-S mean ratings (including 35 items, 11 components, 3 subscores, and the Overall Stuttering Score). The mean Cohen's d effect sizes for these significant pair-wise comparisons are shown in parentheses.

Bosnia \& Herzegovina:

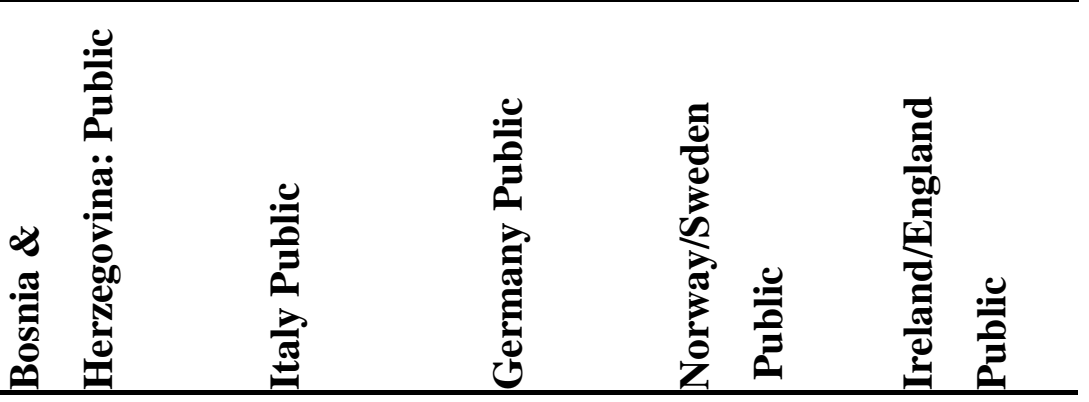

Public

Italy: Public

$67 \%$

Germany: Public

$62 \%$ $67 \%$

Norway/Sweden: Public

$67 \%$ $77 \%$ $52 \%$

Ireland/England: Public $65 \%$ $67 \%$ $42 \%$ $50 \%$ 


\subsubsection{Rating Variability Between Countries II}

As in Study I, mean absolute differences between all pair-wise comparisons between the five countries (in this case, a total of 10) were calculated relative to the -100 to +100 scale range. The variability of summary ratings between countries in Study II was much greater than between regions in Study I. For OSS, the mean variability among the five countries/areas was 16.2 units on the scale, for Beliefs, 29.8 units, for Self Reactions, 26.3 units, for Obesity/Mental Illness, 16.4 units and for all POSHA-S ratings, 25.9 units. Most importantly, rating variability (ranging from 16 to 26 scale units) was an average of 2.2 to 3.7 times greater than for the within-country region percentages in Study I, confirming much greater public attitude variability in Study II.

\subsubsection{Rank Order Predictors Between Countries II}

The fourth purpose of this investigation was to attempt to identify predictors of the rank orders of country/area differences, if such differences were apparent. Indeed, large differences were apparent. Would any of demographic variables such as age, education, sex, and self-ratings predict the rank orders of the summary stuttering ratings (OSS, Beliefs subscore, and Self Reactions subscore) for the five samples? In other words, if a variable was important in predicting OSS, for example, it would follow that the rank order among the five countries for that variable would be the same as for the OSS.

Italian and Scandinavian respondents were the oldest and Irish/English respondents were the youngest; thus, age did not appear to consistently predict the rank order for attitudes. The Italian sample had slightly more males than the other groups, and the Scandinavians the least, but this was deemed to have a minimal effect on the results, if any (see section 4). The socioeconomic variable of relative income did not follow the country/area ranking either, with Bosnia 
\& Herzegovina the lowest, and Germany the highest. Study I clearly showed that religion in Bosnia \& Herzegovina, the only country wherein regions were selected partly to represent different religions, likely had only a small effect, if any, on the measured stuttering attitudes. Previous studies (e.g., Abdalla \& St. Louis, 2012; 2014; Al-Khaladi et al, 2009; Özdemir et al., 2011a, 2011b) have suggested that Middle Eastern respondents, the large majority of whom were Muslims, had less positive attitudes than some Western samples. The implication was advanced that religion may have played a role in their more negative attitudes. In Bosnia \& Herzegovina, however, the central and primarily Muslim region manifested slightly more positive attitudes than the primarily Orthodox or Catholic regions.

The lowest Italian POSHA-S ratings might seem to be related to their highest percentage reporting knowing nobody who stutters (54\%). Nevertheless, the lowest percentage reported by the Bosnian \& Herzegovinians (14\%), followed by the Scandinavians and Germans (20\% and $25 \%$ ), and the second highest percentage (44\%) by the Irish/English, again, does not follow the OSS or stuttering subscore rankings. We further considered whether or not respondents' exposure to or knowledge of stuttering might explain the country/area differences. None of the three items in the Knowledge component matched the summary attitude rankings of the five countries. From highest (more positive) to lowest, ranks for the rated amount known about stuttering was Bosnia \& Herzegovina, Germany, Ireland/England, Italy, and Norway/Sweden. The high to low ranks for the formula-generated item of persons known who stutter (from self to nobody) were Germany-Bosnia \& Herzegovina-Norway/Sweden (tied), followed by Ireland/England, and then Italy. The source of knowledge from personal experience ranked as follows: Norway/Sweden, Germany, Italy, Ireland/England, and Bosnia \& Herzegovina.

Health and abilities or life priorities did not appear to be systematically related to the 
groups' stuttering attitude rankings either. For example, although $8 / 10$ of the pair-wise country differences were significant, the only two nonsignificant priority comparisons related to helping the less fortunate between Norway/Sweden vs. Italy and between Germany and Ireland/England.

For any POSHA-S rating, the number of five potential country/area rank order permutations is 120 or [5!]. To quantify all similarities or differences in ranks for the abovementioned and all other $P O S H A-S$ variables, we first rank-ordered each country/area rating from highest to lowest and assigned the ranks of 1, 2, 3, 4, or 5 accordingly. Next, we compared those ranks to ranks of the POSHA-S OSS and three subscores (Beliefs, Self Reactions, and Obesity/Mental Illness). We calculated the absolute (without regard to plus or minus) mean difference between each rank order of all the POSHA-S variables and the four summary variables (subscores and OSS), and summed those for the five countries/areas. Identical ranks would generate a summed rank score of 0 (e.g., Absolute $((1-1)+(4-4)+(5-5)+(2-2)+(3-3))=$ 0), whereas several highly divergent rankings would generate a maximum rank score of 12 (e.g., Absolute $((1-5)+(2-4)+(3-3)+(4-2)+(5-1))=12)$. These ranks are shown in Supplementary Dataset C.

Considering only rank scores of 0 (identical ranks), the following variables were the same as the OSS ranking: the helping/accommodating component and the concern if "I" stuttered (item). Four ratings had the same ranks as the Beliefs subscore: cause (component), not telling a stuttering person to "slow down" or "relax" (item), and not being concerned if a neighbor or sibling stuttered (items). Ranks for seven ratings were identical to the Self Reactions subscore rank: self-rating of mental health (item), believing stuttering persons can lead a normal life (item), social distance/sympathy (component), being comfortable around a stuttering person (item), impression of stuttering (item), source of stuttering knowledge from school (item), and 
impression of mental illness (item). Self-ratings of physical health and life priority of earning money items had the same ranks as the Obesity/Mental Illness subscore rank.

Numerous other variables had ranks that differed only by 2 (i.e., two adjacent ranks reversed, e.g., Absolute $((1-1)+(4-4)+(5-5)+(2-3)+(3-2))=2)$. Interestingly, however, none of these identical or close-ranking variables were the expected demographic variables of age, sex, income, single, married, parent, student, working, not working, retired, self identification of the various general attributes (except for the self identification of stuttering item compared to the Beliefs subscore), or knowing no one with the attributes. Also, very few ranks of the health and abilities items or life priority items generated close rankings either. Instead, the subscore and OSS ranks were best predicted by various $P O S H A-S$ attitude ratings. Adding the four difference scores together, the two POSHA-S ratings that most closely predicted all four of the summary ratings (three subscores and OSS), with summed values of 12, were the helping/accommodating component and concern if "I" stuttered item.

Overall, demographic and related variables, while most likely having some impact on stuttering attitudes in each country, probably had little common influence on the country/area ranking in Study II. As such, they do not appear to provide clear enough differences to be seriously considered as primary contributors to the rank order differences observed. Taken together, it appeared that a complex interaction of factors and, very likely, factors not considered in this investigation were responsible for the differences in the ranks of more or less positive stuttering attitudes among the five countries/areas.

\section{DISCUSSION}

Study II provides a broad snapshot of public attitudes toward stuttering in Europe. With more than 1100 respondents from five countries or related areas, and in six different languages, it 
showed that national boundaries are important factors to consider in isolating predictors of stuttering attitudes. Study I serves as an important control study to corroborate these findings. It showed that in three independent investigations using the POSHA-S, geographic regional differences within three of the five countries or areas of Study II had minor impacts on measured stuttering attitudes. Accordingly, the large differences in attitudes observed in comparisons of Bosnia \& Herzegovina, Italy, Germany, Norway/Sweden, and Ireland/England are most likely affected strongly by a complex interaction of yet-to-be identified variables. It is likely that some of the demographic variables considered in the rank-order comparisons play a role, but other factors related to national identities or close geographically-related national identities appear to be even more important.

The finding of large between-country differences was unexpected. It has been assumed that public attitudes toward stuttering in Western Europe are quite similar, regardless of country or language, and that these attitudes are similar to those in North America (e.g., Daly \& Leahy, 2014; Preus, 1981; Valente, Jesus, Leahy, \& St. Louis, 2014). The results of this study suggest that this assumption must be reconsidered. Our results suggest that Italians hold attitudes toward stuttering that are more negative than average, similar to those that been variously reported in Middle Eastern respondents (e.g., Abdalla \& St. Louis, 2012; Al-Khaladi et al., 2009; Özdemir et al., 2011a, 2011b) or Chinese respondents (Ip et al., 2012). Moreover, these somewhat negative attitudes are found all across Italy. By contrast, Norwegians and Swedes hold more positivethan-average public attitudes that are similar to better-than-average attitudes reported for speechlanguage pathologists (SLP)s or SLP students (St. Louis, Przepiorka, et al., 2014). Irish/English and Bosnian \& Herzegovinian attitudes are lower but typically above average. German attitudes are the most similar to the median values in the POSHA-S database, as are public stuttering 
attitudes in Poland (Przepiórka et al., 2013) and Portugal (Valente, et al., 2014). Ratings for all three regions within the three European countries in Study I varied from one another by $2 \%$ to $8 \%$ of the -100 to +100 scale (4 to 16 units) while for five countries or areas in Study II, they varied from $8 \%$ to $15 \%$ (16 to 30 units), or an average of 2 to 4 times greater.

These differences highlight issues that can be uncovered in large, epidemiological investigations of stuttering attitudes. They draw attention to variables that easily go unnoticed in studies that compare samples within one country or possibly between samples in two countries (e.g., St. Louis, Abdalla, et al., 2014; St. Louis, LeMasters, et al., 2015; St. Louis, Przepiórka, et al., 2014; St. Louis, Sønsterud, et al., 2014; Tyrrell, 2011). The question arises, "What are the epidemiological variables that are most likely responsible for the inter-country differences we have observed?" We have identified country or related-country nationality as the primary factor identified in this study; yet before concluding that national identity was a significant factor, we considered a number of alternate explanations.

The first potentially confounding issue we considered was the fact that some of the sample sizes, e.g., those in Norway, were not large, and that sample size varied across the countries/areas, ranging from 20 to 122 in Study I and 128 to 300 in Study II. As of November, 2015, the mean sample size for all 135 POSHA-S investigations in the POSHA-S database was 62. St. Louis (2008) carried out a comparison of five different sample sizes and different sampling strategies to determine representativeness of the mean of the 2000-respondent database at that time. A sample size of 50 generated means that were virtually as close to the overall POSHA-S item means as did samples of 100 or 200. Smaller samples of 25 generated quite similar means, but samples of 12 generated less reliable matches. At each sample size, representative samples more closely approximated the overall means than convenience samples. 
For the current study, we carried out a similar procedure where we separately reanalyzed all the means for each country/area in Study II ( $\mathrm{n}=128$ to 300) using subsets of 100, 50, and 25 randomly selected respondents. Using all three sample sizes and disregarding plus or minus values, we calculated the mean and maximum difference between the new and original values for each POSHA-S rating for each country/area. For all 60 POSHA-S ratings combined, mean variability ranged from 5.0 to 7.6 units of the -100 to +100 scale range. One or two individual items or components for two countries generated maximums of 39.0 to 40.3 units for German and Norwegian/Swedish samples, but the other three countries had maximum variability of 19.8 to 27.0 units. Considering only the Beliefs and Self Reactions subscores and OSS, means varied from 0.5 to 5.5 units. Maximum percentage differences were 1.0 to 8.4 units. Given these very small differences, we concluded that our results were not adversely affected by small or differing sample sizes.

We also considered that differences in sampling procedures among the five regions, another limitation of the current study, may explain the differences observed. Obviously, there were sampling differences (i.e., all were convenience samples with some restrictions except the quasi-probability Irish sample and part of the Swedish sample [which was from a probability sample]). If the similar populations are sampled, differences from one convenience sample to another typically make little difference in measured public attitudes. For example, three studies using the POSHA-S with three different convenience sampling procedures resulted in very similar results for Turkish adults (Aydın, 2008; St. Louis, et al., 2005; St. Louis, Filatova et al., 2011), and another study showed no differences between paper versus online responding (St. Louis, 2012a). Indeed, the three regional samples in Norway were obtained by different coinvestigators, operating independently, and the Swedish sample was carried out later with 
different purposes and by different investigators. Even so, Scandinavian samples had the most positive attitudes, a finding similar to the best attitudes reported from Denmark in a comparison of numerous samples from Europe, North America, the Middle East, and Africa in the first pilot studies with an experimental version of the POSHA instrument (Knudsen, Kathard, St. Louis, \& Shrestha, 2004).

Additionally, we considered the fact that different translations of the POSHA-S were utilized. We cannot rule out the potential confounding of different translations, and the literature indicates that some confounding is inevitable (Acquadro, Conway, Hareendran, \& Aaronson, 2008; Rogler, 1999; Valente, Jesus, Roberto, Leahy, \& St. Louis, in press). Nevertheless, the POSHA-S has been translated into 23 different languages (as of November, 2015) with remarkably similar results (e.g., St. Louis, 2012b; St. Louis, Filatova, et al. 2011). In carefully designed studies to investigate translations, St. Louis and Roberts $(2010,2013)$ showed that Canadians who filled out experimental versions of the POSHA-S in either English or French had equivalent attitudes. The same results occurred with respondents from Cameroon. As has been explained (St. Louis, 2005; St. Louis et al., 2008; St Louis, 2012b), the POSHA-S was specifically designed to foster accurate translations, e.g., using simple, direct language and avoiding slang. Additionally, the final item selection was informed by empirically discovered difficulties in translations resulting in a few items being deleted (St. Louis, 2012b).

As noted, in Norway (Study I), investigators provided a written definition of stuttering (and in the relevant samples, a parallel definition of cluttering [c.f., St. Louis, Sønsterud, et al., 2014]). We considered the effect of this limitation and the effect it may have had on the results. Three arguments suggest that it did not. First, the addition of the Swedish sample, although somewhat less positive than the Norwegian contingent, still had the second most positive 
attitudes of all the country groups. This is consistent with an early report of the first experimental version of the POSHA-S wherein the most positive attitudes observed from eight different countries were obtained from another Scandinavian country, i.e., Denmark (Knudsen et al., 2004). Secondly, extremely small or no differences have been observed in comparisons of samples from other countries wherein POSHA-S ratings were obtained without a written definition of stuttering versus those that used the same lay definition of stuttering as in the Norwegian study. (These studies were designed to compare attitudes toward cluttering with those toward stuttering in the same investigations. Since cluttering was assumed to mean "messy" in the general population rather than a fluency disorder, lay definitions were provided of both cluttering and stuttering.) We compared stuttering attitude results of studies that included lay definitions with studies from Turkey and the USA wherein the POSHA-S was administered in the standard way without a definition (i.e., Aydın, 2008; St. Louis, Aliveto et al., 2009; St. Louis, Andrade, Georgieva, \& Troudt, 2005; St. Louis, Filatova, et al., 2011; St. Louis, Reichel et al., 2009). Beliefs, Self Reactions, and OSSs varied in the Turkish studies by only 1, 6, and 3 units on the scale, respectively, and the American samples varied only by 6, 4, and 5 units. Third, as a direct check, we subsequently administered the standard POSHA-S to a small control sample of 18 Norwegian adults and compared their results to the combined Norwegian sample from Study I. Stuttering attitudes of the control sample were strikingly similar to those of respondents from the Study I respondents. Their Obesity/Mental Illness subscores differed by 1 unit, Beliefs by 5 units, Self Reactions by 4 units, and the OSS by 1 unit. All of these comparisons strongly suggest that the written definition did not affect the results sufficiently to change the outcome of the most positive attitudes observed for the Norwegian respondents.

This leaves factors related to one's nationality as the most likely predictors of observed 
differences in measured attitudes toward stuttering in these five European countries/areas. We have not yet identified what those predictors are. Clearly, an indefinitely large number of factors affecting national identity are beyond the scope of this study. Accordingly, our results highlight the potential value of a number of investigations that could be undertaken. First, this study could serve as a pilot study for large epidemiological studies of Europe and other regions (e.g., the Middle East or the Caribbean) all carried out with a standard probability sampling method to determine the robustness of the results of Study II and to extend them to other regions. In such studies, we recommend the inclusion of a standard measure of national identity (e.g., Rusciano, 2003) that potentially could explicate some of the relevant predictor variables. Second, studies using a uniform probability sampling scheme, such as was carried out successfully in the entire country of Portugal (Valente et al., 2014), in a smaller multinational study would elucidate the extent to which differences in convenience sampling in the various samples might have affected the results in this study, a notable weakness. Although perhaps less likely to show a difference in probability versus convenience sampling than in Turkey where education differences were large (Özdemir et al., 2011a), it is possible that probability sampling in Europe would generate different country profiles. Third, assuming that the findings of this study are robust, it would be useful to explore the attitudes of children versus adults who stutter in these and other European countries to determine whether or not they might be differentially affected by the public's attitudes. A study of persons who stutter might well include a standard measure such as the POSHA-S as well as a measure of the quality of life, e.g., the Overall Assessment of the Experience of Stuttering (OASES) (Yaruss \& Quesal, 2008) or the St. Louis • Inventory of Life Perspectives-Stuttering (SL $\bullet I L P-S)$ (St. Louis, 2001). Fourth, a multi-national study using the same procedures to change stuttering attitudes (e.g., Abdalla \& St. Louis, 2014; Flynn \& St. 
Louis, 2011) might further elucidate important variables affecting differential persistence of public attitudes toward stuttering, especially since some recent efforts to improve attitudes have not been successful (Kuhn \& St. Louis, 2015; Węsierska, Błachnio, Przepiórka, \& St. Louis, 2015). Fifth, relevant translations in different countries using a new clinical measure that is similar to an earlier, experimental version of the POSHA-S, the Appraisal of the Stuttering Environment (ASE) could be given to family and close friends of Europeans who stutter to determine the effect of the stuttering attitude environment on quality of life, response to therapy, and other variables, such as has been reported in the USA (St. Louis, Kuhn, \& Lytwak, 2015).

\section{Footnotes:}

${ }^{1}$ The written definition provided for the Norwegians in Study I was:

Stuttering refers to a speech disorder in which a speaker typically repeats or prolongs (draws out) parts of words, or gets stuck or blocked on words.

Sometimes stuttering consists of strategies that try to reduce or avoid repeating, prolonging, or blocking. Stuttering is often associated with psychological stress or unpleasant feelings. Finally, the person who stutters often experiences a loss of voluntary control in saying certain words. (cf, St. Louis, Filatova, et al., 2011; St. Louis, Sønsterud, et al., 2014)

${ }^{2}$ In the St. Louis, Sønsterud, et al. (2014) study The location of the Bergen "cluttering only" group was identified, incorrectly, as the "central" region of Norway; it is generally referred to by locals as in the "western" region.

\section{REFERENCES}

Acquadro, C. Conway, K., Hareendran, A., \& Aaronson, N. (2008). Literature review of methods to translate health-related quality of life questionnaires for use in multinational clinical 
trials, Value in Health, 11, 509-521.

Al-Khaledi, M., Lincoln, M., McCabe, P., Packman, A., \& Alshatti, T. (2009). The attitudes knowledge and beliefs of Arab parents in Kuwait about stuttering. Journal of Fluency Disorders, 34, 44-59.

Abdalla, F., \& St. Louis, K. O. (2012). Arab school teachers' knowledge, beliefs and reactions regarding stuttering. Journal of Fluency Disorders, 37, 54-69.

Abdalla, F., \& St. Louis, K. O. (2014). Modifying attitudes of Arab school teachers toward stuttering. Language, Speech, and Hearing Services in the Schools, 45, 14-25.

Aydın, C. (2008). Kekemeliğe yönelik toplumsal farkındalı̆̆ın belirlenmesi (Determining awareness toward stuttering). Unpublished Master's Thesis. Eskişehir, Turkey: Anadolu University.

Alshdifat, K., Mayo, R., and St. Louis, K. O., 2013, Attitudes of Jordanians toward stuttering and people who stutter. Technical session presented at the Annual Convention of the American Speech-Language-Hearing Association. Chicago, IL.

Arnold, H. S., Li, J., \& Goltl, K. (2015). Beliefs of teachers versus non-teachers about people who stutter. Journal of Fluency Disorders, 43, 28-39.

Beste-Guldborg, A. M., St. Louis, K. O., \& Campanale, N. (2015). American Indian perceptions of stuttering. In K. O. St. Louis (Ed.), Stuttering meets stereotype, stigma, and discrimination: An overview of attitude research. (pp. 133-145). Morgantown, WV: West Virginia University Press.

Błachnio, A., Przepiórka, A., St. Louis, K. O., Węsierska, K., \& Węsierska, M. (2015). Postawy społeczne wobec jąkania w Polsce - Przegląd badań z użyciem POSHA-S [Social attitudes towards stuttering in Poland - An overview of research using the POSHA-S]. In 
K. Węsierska (Ed.). Zaburzenia płynności mowy - teoria i praktyka [Fluency disorders: Theory and practice] (pp. 89-99), Wydawnictwo Uniwersytetu Śląskiego w Katowicach [Katowice, Poland: University of Silesia Press].

Bloodstein, O., \& Ratner, N. B. (2008). A Handbook on Stuttering (6th ed.). New York: Thomson-Delmar.

Boyle, M. P., \& Blood, G. W. (2015). Stigma and stuttering: conceptualizations, applications, and coping. In K. O. St. Louis (Ed.), Stuttering meets stereotype, stigma, and discrimination: An overview of attitude research (pp. 43-70). Morgantown, WV: West Virginia University Press.

Cohen, J. (1988). Statistical power for the behavioral sciences. ( $2^{\text {nd }}$ ed.). Hillsdale, NJ: Erlbaum. Coşkun, M. (2006). Kekemelik ve hızlı-bozuk konuşma hakkında farkındalı̆̆ın betimlenmesi (Describing awareness about stuttering and cluttering). Unpublished Master's Thesis. Eskişehir, Turkey: Anadolu University

Daly, C., \& Leahy, M. (2014). Public attitudes towards stuttering: An epidemiological study of an Irish population. Paper presented at the European Symposium on Fluency Disorders. Antwerp, Belgium.

de Britto Pereira, M. M., Rossi, J. P., \& Van Borsel, J. (2008). Public awareness and knowledge of stuttering in Rio de Janeiro. Journal of Fluency Disorders, 33, 24-31.

Elsiddig, Y., Haynes, C., Atwood, J., \& St. Louis, K. O. (2015). Public attitudes towards stuttering in Khartoum, Sudan. In K. O. St. Louis (Ed.), Stuttering meets stereotype, stigma, and discrimination: An overview of attitude research (pp. 146-153). Morgantown, WV: West Virginia University Press.

Fagerland, M. W. (2012). T-tests, nonparametric tests, and large studies-A paradox of 
statistical practice? BMC Medical Research Methodology, 12, 78-84.

Flynn, T. W., \& St. Louis, K. O. (2011). Changing adolescent attitudes toward stuttering. Journal of Fluency Disorders, 36, 110-121.

Ip, M. L., St. Louis, K. O. Myers, F. L., \& An Xue, S. (2012). Stuttering attitudes in Hong Kong and Mainland China. International Journal of Speech-Language Pathology, 14, 543-556.

Knudsen, P. F., Kathard, H., St. Louis, K. O., \& Shrestha, S. (2004, November). Selected Attitudes Toward Stuttering: Denmark, South Africa, and Nepal (English). Poster presented at the Annual Convention of the American Speech-Language-Hearing Association, Philadelphia, PA.

Kuhn, C. D. \& St. Louis, K. O. (2015, November). Attitudes toward stuttering of middle school students before \& after a stuttering video. Poster presented at the Annual Convention of the American Speech-Language-Hearing Association. Denver, CO.

Li, J., \& Arnold, H. S. (2015). Reactions of teachers versus non-teachers toward people who stutter. Journal of Communication Disorders, 56, 8-18.

Manning, W. H. (2010). Clinical decision making in the diagnosis and treatment of fluency disorders, $3^{\text {rd }}$ ed. Clifton Park, NY: Delmar

Maviş, İ, St. Louis, K. O., Özdemir, S., \& Toğram, B. (2013). Attitudes of Turkish speech and language therapists toward stuttering. Journal of Fluency Disorders, 38, 157-170.

Nillson, S., \& Wetterling, T. (2013). “Try to relax" - A survey study in Sweden among native Swedes and Arabic immigrants concerning views on stuttering. Unpublished master's Thesis. Lund, Sweden: Lund University.

Özdemir, R. S., St. Louis, K. O., \& Topbaş, S. (2011a). Public attitudes toward stuttering in Turkey: Probability versus convenience sampling. Journal of Fluency Disorders, 36, 
262-267.

Özdemir, R. S., St. Louis, K. O., \& Topbaş, S. (2011b). Stuttering attitudes among Turkish family generations and neighbors from representative samples. Journal of Fluency Disorders, 36, 318-333.

Preus, A. (1981). Identifying subgroups of stutterers. Oslo: Universitetsforlaget.

Przepiórka, A., Błachnio, A., St. Louis, K. O., \& Wozniak, T. (2013). Public attitudes toward stuttering in Poland. International Journal of Language and Communication Disorders, $48,703-714$.

Rogler, L. H. (1999). Methodological sources of cultural insensitivity in mental health research. American Psychologist, 54, 424, 433.

Rusciano, F. L. (2003). The construction of national identity-A 23-nation study. Political Research Quarterly, 56, 361-366.

Shapiro, D. A. (2011). Stuttering intervention. Austin, $2^{\text {nd }}$ ed., TX: Pro-ed.

Silva, M., Leal, G., Correia, P., Valente, A., \& St. Louis, K. O. (in press). Teachers' beliefs and attitudes toward children who stutter. Proceedings of the $8^{\text {th }}$ World Congress on Fluency Disorders. International Fluency Association.

St. Louis, K. O. (2001). Living with stuttering: Stories, basics, resources, and hope. Morgantown, WV: Populore.

St. Louis, K. O. (2005). A global project to measure public attitudes of stuttering. The Asha Leader, 10, 12-13; 22.

St. Louis, K. O. (2008, November). Surveying public attitudes toward stuttering: Considerations of sample size. Technical paper presented at the Annual Convention of the SpeechLanguage-Hearing Association. Chicago, IL. 
St. Louis, K. O. (2011a). International project on attitudes toward human attributes (IPATHA). Morgantown, WV: Populore. 〈http://www.stutteringattitudes.com>.

St. Louis, K. O. (2011b). The Public Opinion Survey of Human Attributes-Stuttering (POSHAS): Summary framework and empirical comparisons. Journal of Fluency Disorders, 36, 256-261.

St. Louis, K. O. (2012a). POSHA-S public attitudes toward stuttering: Online versus paper surveys. Canadian Journal of Speech-Language Pathology and Audiology, 36, 116-122.

St. Louis, K. O. (2012b). Research and development for a public attitude instrument for stuttering. Journal of Communication Disorders, 45, 129-146.

St. Louis, K. O. (2015a). Epidemiology of public attitudes toward stuttering. In K. O. St. Louis (Ed.), Stuttering meets stereotype, stigma, and discrimination An overview of attitude research (pp. 7-42). Morgantown, WV: West Virginia University Press.

St. Louis, K. O. (Ed.). (2015b). Stuttering meets stereotype, stigma, and discrimination: An overview of attitude research. Morgantown, WV: West Virginia University Press.

St. Louis, K. O. (in press). Worldwide perspectives on public \& professional attitudes toward fluency disorders. Proceedings of the $8^{\text {th }}$ World Congress on Fluency Disorders. International Fluency Association.

St. Louis, K. O., Abdalla, F., Burgess, M. E., \& Kuhn, C. D. (2015). Public attitudes toward mild versus severe stuttering in the USA and Kuwait. In K. O. St. Louis (Ed.), Stuttering meets stereotype, stigma, and discrimination: An overview of attitude research (pp. 154-164). Morgantown, WV: West Virginia University Press.

St. Louis, K. O., Andrade, C. R. F, Georgieva, D., \& Troudt, F. O. (2005). Experience and personal report about an international cooperation research-Brazil, Bulgaria and 
Turkey_Attitudes Toward Stuttering. Pró-Fono Revista de Atualização Cientifica, 17, 413-416.

St. Louis, K. O., Filatova, Y., Coşkun, M., Topbaş, S., Özdemir, S., Georgieva, D., McCaffrey, E., \& George, R. D. (2011). Public attitudes toward cluttering and stuttering in four countries. In E. L. Simon (Ed.) Psychology of stereotypes. (pp. 81-113). Hauppauge, NY: Nova Science Publishers.

St. Louis, K. O., Kuhn, C. D., \& Lytwak, L. (2015). The Appraisal of the Stuttering Environment (ASE): A new clinical tool to measure stuttering attitudes the client's environment. In K. O. St. Louis (Ed.), Stuttering meets stereotype, stigma, and discrimination: An overview of attitude research (pp. 255-273). Morgantown, WV: West Virginia University Press.

St. Louis, K. O., LeMasters, S. N., \& Poormohammad (2015). Public attitudes toward males versus females who stutter: USA and Iran. In K. O. St. Louis (Ed.), Stuttering meets stereotype, stigma, and discrimination: An overview of attitude research (pp. 165-177). Morgantown, WV: West Virginia University Press.

St. Louis, K. O., Lubker, B. B., Yaruss, J. S., Adkins, T. A., \& Pill, J. C. (2008). Development of a prototype questionnaire to survey public attitudes toward stuttering: Principles and methodologies in the first prototype. The Internet Journal of Epidemiology, 5(2). <http://www.ispub.com/journal/the-internet-journal-of-epidemiology/volume-5-number2/development-of-a-prototype-questionnaire-to-survey-public-attitudes-toward-stutteringprinciples-and-methodologies-in-the-first-prototype.html>

St. Louis, K. O., Lubker, B. B., Yaruss, J. S., \& Aliveto, E. F. (2009). Development of a prototype questionnaire to survey public attitudes toward stuttering: Reliability of the second prototype. Contemporary Issues in Communication Sciences and Disorders, 36, 
101-107.

St. Louis, K. O., Przepiórka, A. M, Beste-Guldborg, A., Williams, M. J., Blachnio, A., Guendouzi, J., Reichel, I. K., \& Ware, M. B. (2014). Stuttering attitudes of students: Professional, intracultural, and international comparisons. Journal of Fluency Disorders, $39,34-50$.

St. Louis, K. O., Reichel, I., Yaruss, J. S., \& Lubker, B. B. (2009). Construct and concurrent validity of a prototype questionnaire to survey public attitudes toward stuttering. Journal of Fluency Disorders, 34, 11-28.

St. Louis, K. O., \& Roberts, P. M. (2010). Measuring attitudes toward stuttering: English-toFrench translations in Canada and Cameroon. Journal of Communication Disorders. 43, $361-377$.

St. Louis, K. O., \& Roberts, P. M. (2013). Public attitudes toward mental illness in Africa and North America. African Journal of Psychiatry, 16, 123-133.

St. Louis, K. O., Sønsterud, H., Carlo, E. J., Heitmann, R. R., \& Kvenseth, H. (2014). Public attitudes toward — and identification of — cluttering and stuttering in Norway and Puerto Rico. Journal of Fluency Disorders, 42, 21-34.

St. Louis, K. O., Sønsterud, H., Heitmann, R. R., Kvenseth, H., Flobakk, C., \& Helmen, L. N. (2012, July). Identification of cluttering and/or stuttering by the public in three regions of Norway. Paper presented at the $7^{\text {th }}$ World Congress on Fluency Disorders. International Fluency Association, Tours, France.

St. Louis, K. O., Weidner, M. E., Gabel, R., Hughes, S., \& Coleman, C. (2014). Stuttering Attitudes Research Symposium: Reflecting on a landmark event. Perspectives on Fluency and Fluency Disorders, 24, 5-7. 
St. Louis, K. O., Williams, M. J., Ware, M. B., Guendouzi, J., \& Reichel, I. (2014). The Public Opinion Survey of Human Attributes-Stuttering $(P O S H A-S)$ and Bipolar Adjective Scale (BAS): Aspects of validity. Journal of Communication Disorders, 50, 36-50.

Stonehouse, J. M., \& Forrester, G. J. (1998). Robustness and the $t$ and U tests under combined assumption violations. Journal of Applied Statistics, 25, 63-74.

Theiling, M. (2013). Öffentliche Wahrnehmung von Stotternden in Deutschland -Erprobung und Validierung der deutschen Version des POSHA-S [Public perception of people who stutter in Germany - Testing and validation of the German version of the POSHA-S.] Unpublished Master's thesis, RWTH Aachen University, Aachen, Germany.

Tomaiuloi, D., Del Gado, F., Caparelli, E., \& St. Louis, K. O. (2013, August). Stuttering attitudes in Italy. Paper presented at the $29^{\text {th }}$ World Congress of the International Association of Logopedics and Phoniatrics, Turin, ITALY

Tyrrell, L. (2009). A comparison of the attitudes, knowledge and beliefs about stuttering in British university students living in the UK and Syrian university students living in Syria. MSc Dissertation, Speech \& Language Pathology, Reading, UK: University of Reading. Valente, A. R., Jesus, L., Leahy, M., \& St. Louis, K. O. (2014, March) Attitudes and knowledge of the Portuguese population about stuttering. Paper presented at the European Symposium on Fluency Disorders. Antwerp, Belgium.

Valente, A. R. S., Jesus, L. M. T., Roberto, M. T., Leahy, M. M., \& St. Louis, K. O. (in press). Cross-cultural adaptation of the Public Opinion Survey of Human Attributes-Stuttering (POSHA-S): The European Portuguese (EP) translation and adaptation process as a model. Stuttering: Risk factors, public attitudes and impact on psychological well-being. Hauppaguge, NY: Nova Science Publishers. 
Van Borsel, J., Verniers, I., \& Bouvry, S. (1999). Public awareness of stuttering. Folia Phoniatrica and Logopaedica, 51, 124-132.

Węsierska, K., Błachnio, A., Przepiórka, A., St. Louis, K. O. (2015, October). Zmiana postaw wobec jąkania w Polsce - wstępne doniesienia z badań [Changing attitudes towards stuttering in Poland: Preliminary study report]. Paper presented at the International Conference on Speech-Language Therapy: Modern Trends in Logopaedic Diagnosis and Therapy. Chorzów, Poland.

Węsierska, M., \& St. Louis, K. O. (2014). Comparison of attitudes towards stuttering among Polish and English university students. Chowanna, 42, 263-284.

Woods, C. L., \& Williams, D. E. (1971). Speech clinicians' conceptions of boys and men who stutter. Journal of Speech and Hearing Disorders, 36, 225-234.

Woods, C. L., \& Williams, D. E. (1976). Traits attributed to stuttering and normally fluent males. Journal of Speech and Hearing Research, 19, 267-278.

Xing Ming, J., Jing, Z, Yi Wen, Z, \& Van Borsel, J. (2001). Public awareness of stuttering in Shanghai, China. Logopedics Phoniatrics Vocology, 26, 145-150.

Yairi, E., \& Williams, D. E. (1970). Speech clinicians' stereotypes of elementary-school boys who stutter. Journal of Communication Disorders, 3, 161-170.

Yaruss, J. S., \& Quesal, R. W. (2008). Overall Assessment of the Speaker's Experience of Stuttering (OASES). Minneapolis, MN: Pearson. 


\section{Figure Legends}

Figure 1.

POSHA-S summary ratings from three different regions of Bosnia \& Herzegovinia (B\&H). More positive attitudes are located near the periphery while less positive ones near the center.

Subscores are shown in UPPER CASE, while components following clockwise from each subscore are shown in Title Case. The Overall Stuttering Scores are shown in the bottom right box. Traces for each mean are compared with the highest, lowest, and median sample value observed to date from the POSHA-S database of 135 public samples.

Figure 2.

POSHA-S summary ratings from three different regions of Italy.

Figure 3.

POSHA-S summary ratings from three different regions of Norway.

Figure 4.

POSHA-S summary ratings from five different countries or areas of Europe. 


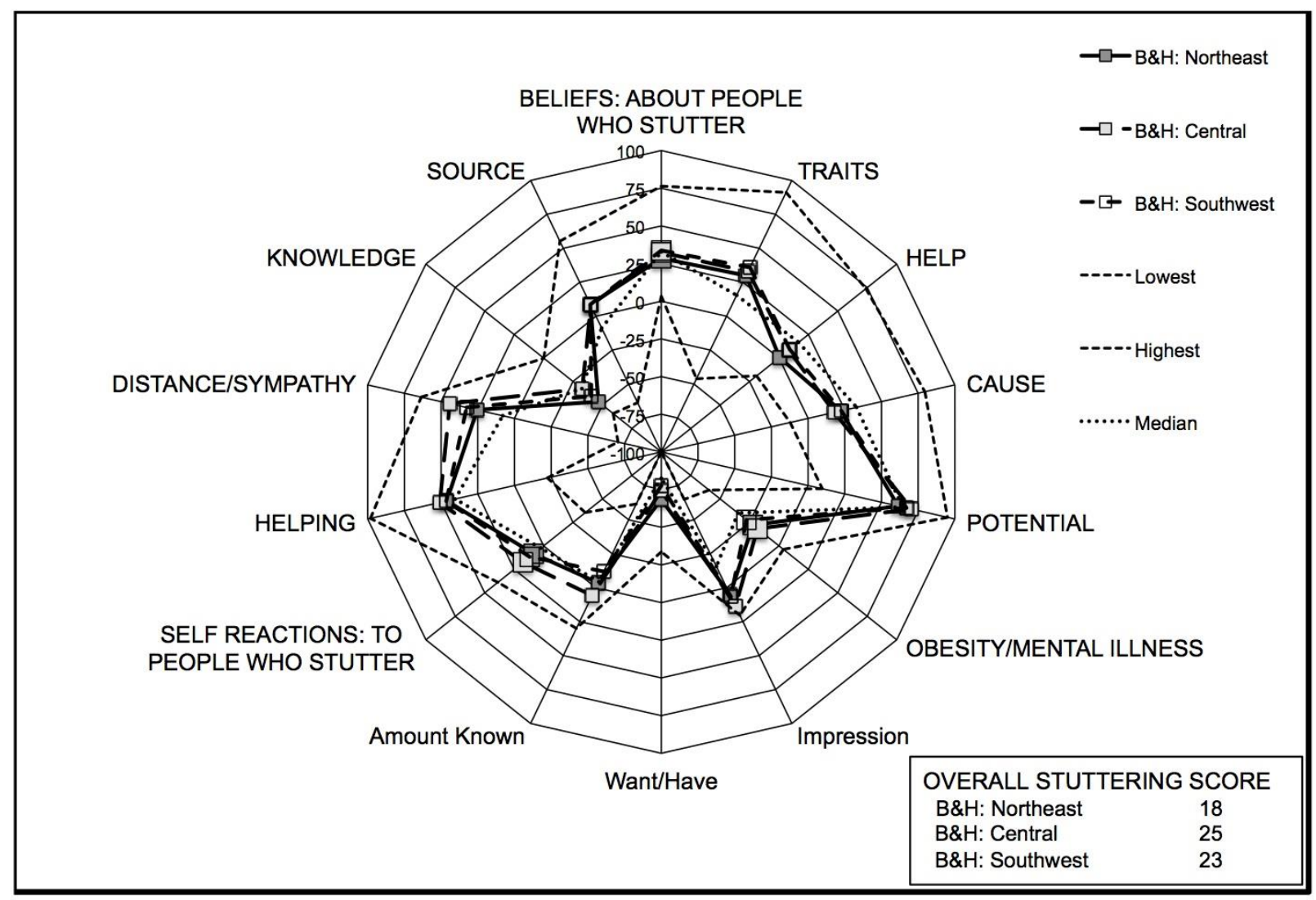




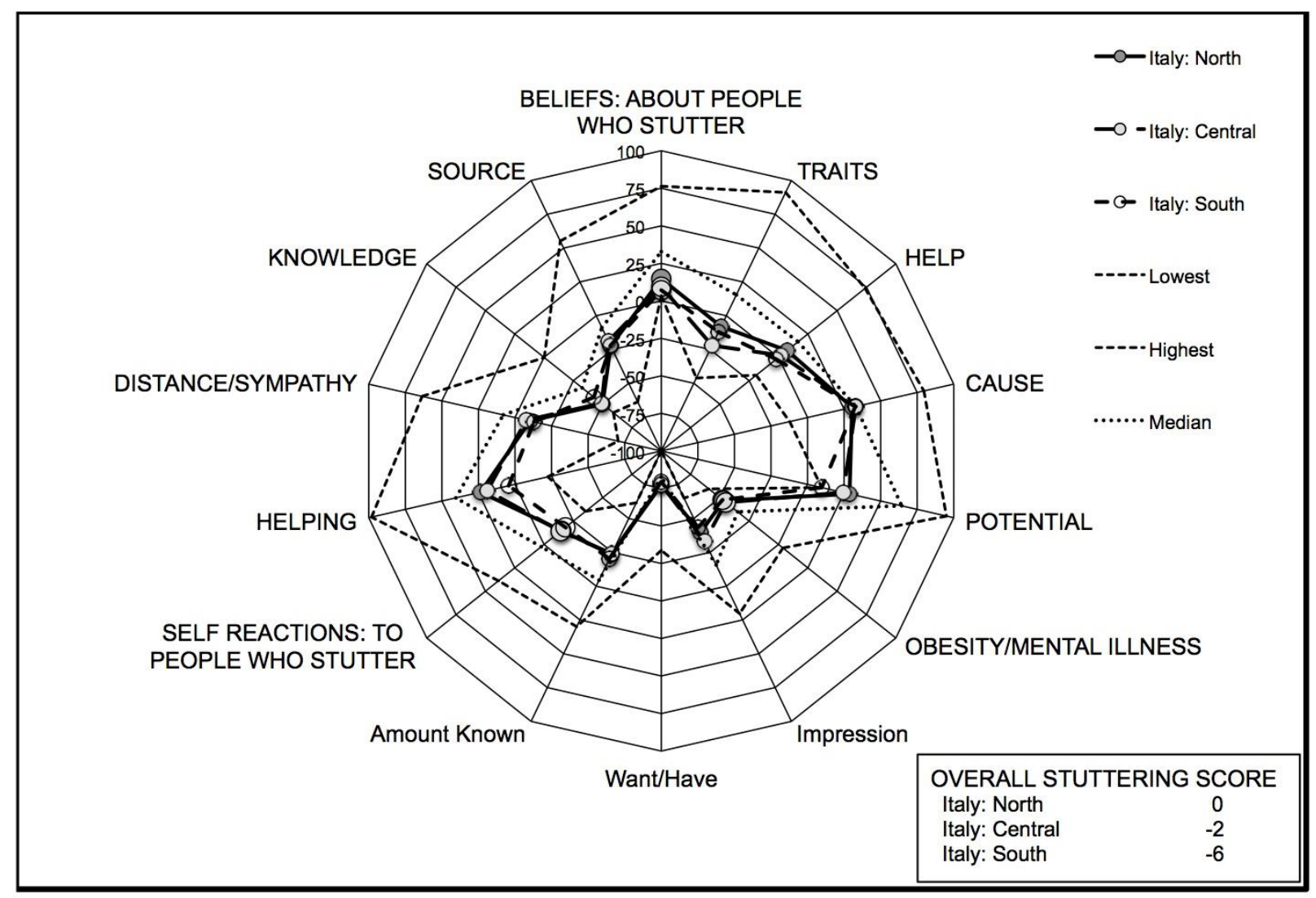




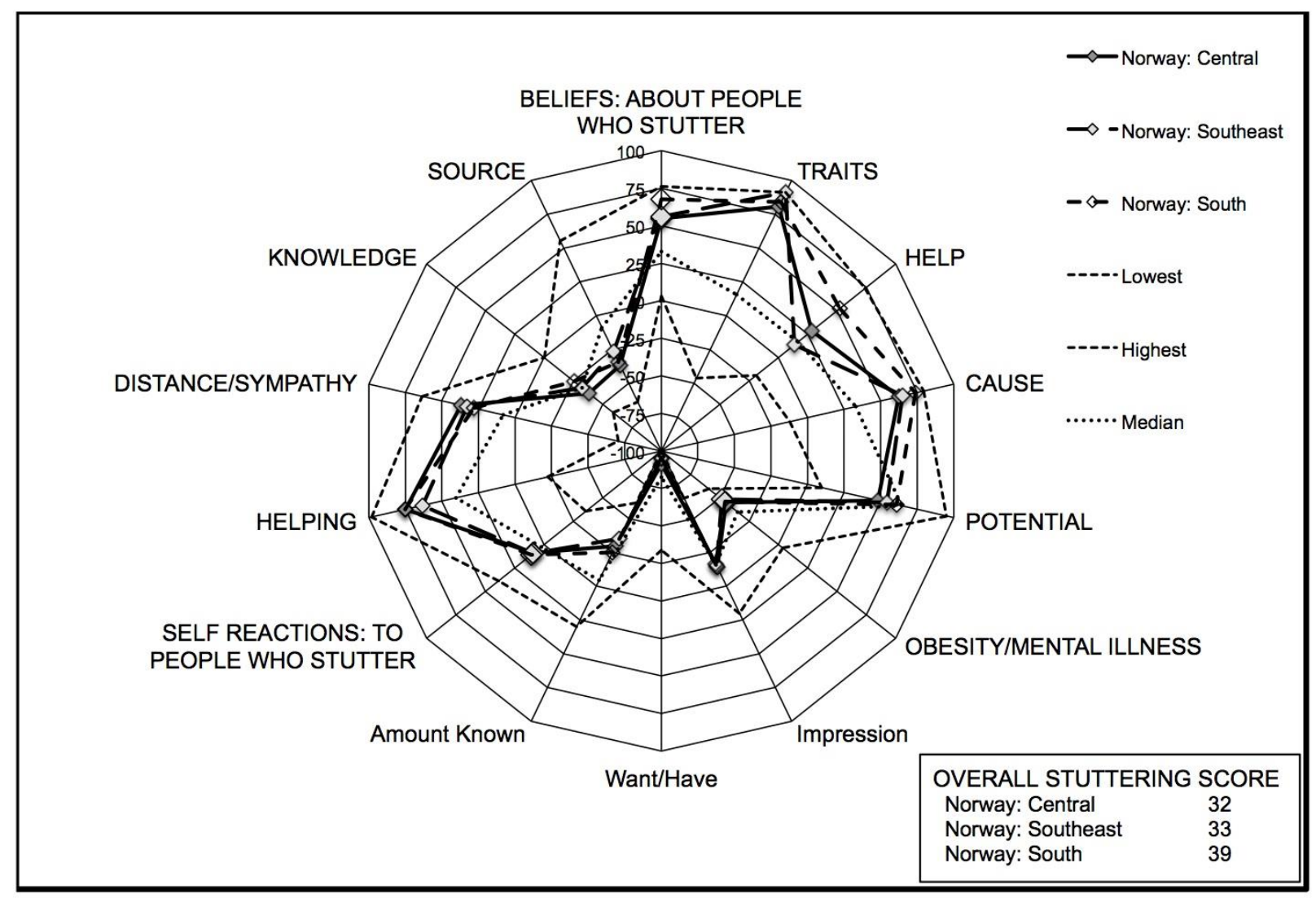




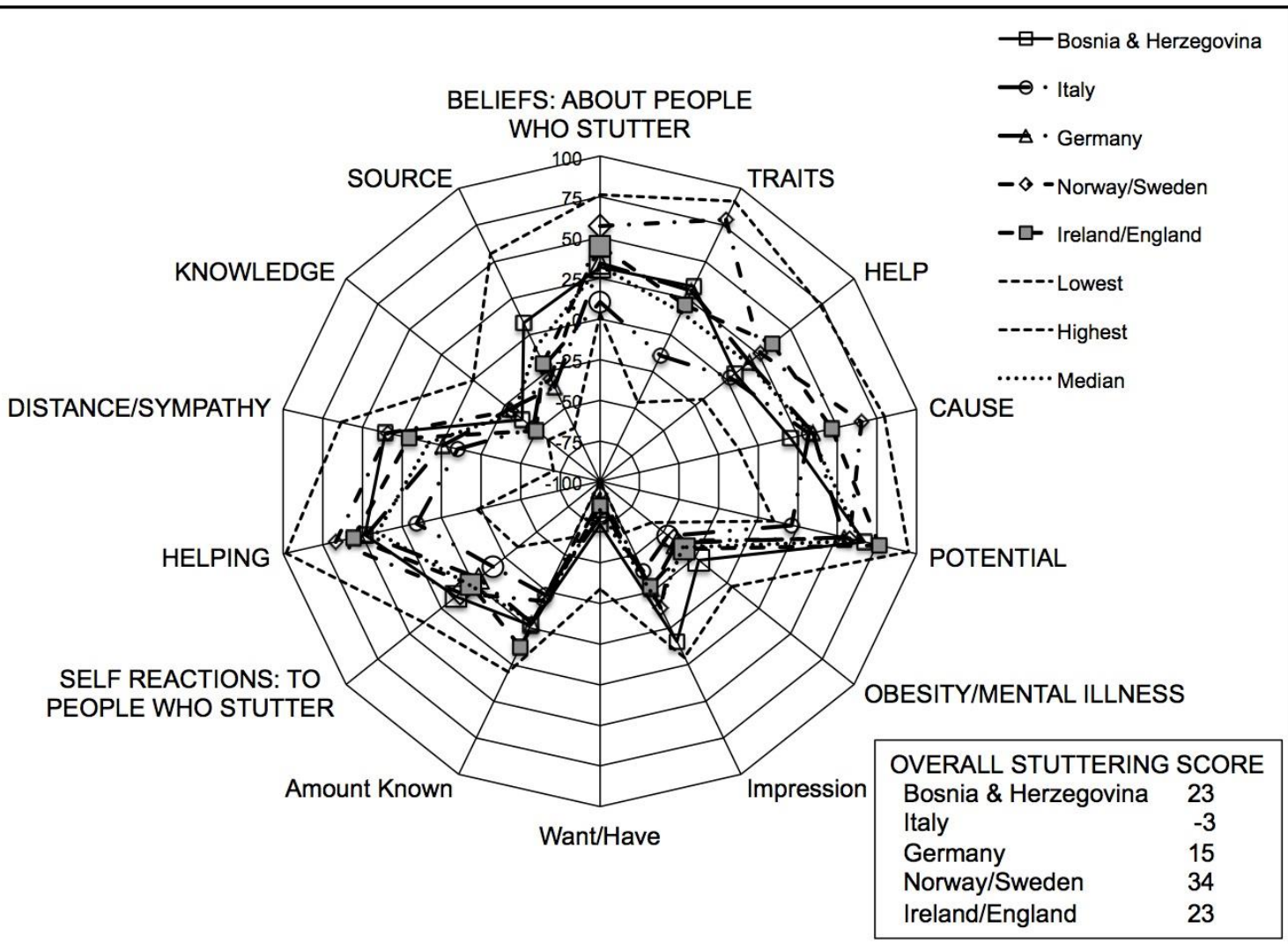

